\title{
Attempts to Diminish the Drawbacks of Polylactic Acid Designed for 3D/4D Printing Technology-Fused Deposition Modeling
}

\author{
DOINA DIMONIE, NICOLETA DRAGOMIR*, RUSANDICA STOICA \\ INCDCP -ICECHIM Bucharest, 202 Splaiul Independentei, 060021, Bucharest, Romania
}

\begin{abstract}
In order to improve thermal behavior and dimensional strability of polylactic acid (PLA) designed both for $3 D$ and $4 D$ printing technology-fused deposition modeling (FDM) using a scalable procedure, the polymer was melt compounded with additives which control the morphology by crystallization and/or reinforcing. Using the formulations which provide polylactic acid (PLA) improved thermo-mechanical properties and desired dimensional stability, the new materials were shaped, on a laboratory line, as filaments for printing technology. The selected compounds were than scaled up on a $50 \mathrm{~kg} / \mathrm{h}$ compounding line into granules which prove to have good shapability as filaments for printing technology (1.85 +/- $0.05 \mathrm{~mm}$ diameter, required ovality, good appearance and smooth surface) and performed properly at $3 D$ printing. The obtained results proved that functional properties of PLA can be improved by various methods so that, depending on the reached performances, the new material can be converted through printing technology into items for performance applications. The novelty of the article is related to the fact that it identifies a modifying solution for controlling the morphology of $a$ type of PLA designed for $3 D$ printing that already has an advanced crystallinity.
\end{abstract}

Keywords: crystallinity, PLA, nucleation, reinforcing, 3D/4D printing technology

\section{Introduction}

The usage of the cumulative /additive fabrication (3D/4D printing technology), including its bio alternative, compared to the subtractive those is particularly attractive mainly because it allows the rapid prototyping and obtaining of items, with complex and/or compact shapes and/or geometries, sometimes with layered structure, well adapted to the market requirements [1]. 4D printing has added time as new dimension to this technology, so that, under the actions of certain stimuli, the new items can undergo changes of shape, color, mechanical properties, etc. [2].

The tendency to replace the materials based on conventional polymers with renewable ones, even for sustainable applications, involves bringing them at the level required by each application in terms of functional properties and dimensional stability, properties of materials to maintain or retain its shape, size or any dimensions, even under varying environmental conditions [2]. It is well known that during fused deposition modelling (FDM) 3D/4D printing the material are subjected to rapid heating and cooling, post fabrication some degree of undesirable warpage of the printed part occurs. The effect can be controlled not only through printing parameters $[3,4]$ but also by improving dimensional stability of the polymeric materials used in printing technologies. Dimensional stability depends on the flexibility of the macromolecules from the amorphous region and regards to internal stress introduced during processing [5]. That is why it is a measurement of the linear dimensional change resulting from exposure to temperature and gives an indication of lot-to-lot uniformity [6].

One of the most used polymers in FDM printing technology is polylactic acid (PLA), a biodegradable and biocompatible polyester of renewable origin [7, 8]. Even the using of PLA in FDM is convenient for many reasons [7] it presents two major disadvantages related to its high heat deformability and brittleness. The improving of PLA quality designed for printing technology is of practical interest taking into consideration its numerous benefits like facile processability, hydrophobicity, transparency, good mechanical properties.

*email:lauranicoleta.dragomir@gmail.com 
By establishing or not of interactions between them, the macromolecules can generate or not a certain order through the arrangement of the chains in crystalline domains, order which can be described at different levels of magnification and which control the polymer properties at macroscopic scale [9, 10]. The ordering or disordering of a polymeric morphology depends on the structure of the macromolecules (chains regularity and symmetry, the polymerization degree, the existence of regular pendant groups, the orientation degree, the chain defects) and the crystallization conditions (cooling rate, crystallization kinetic etc.). The induction of crystallization can be the results of the usage of additives as nucleation agents and/or of procedures as orientation during flowing at melt processing (oriented crystallization), annealing (holding a polymer at an elevated temperature below its melting point or an extra thermal energy) [11,12] drawing above the glass transition [13,14]. The changing of polymeric materials crystallinity generates the enhancement of the glass transition and melting temperature, the increasing of the density, the intensifying of opacity due to the light scattering from crystallites, the improving of the mechanical property, solvent resistance etc. [15].

Modification of polymers through the incorporation of fillers yields to multiphase systems, with unique micro and macrostructures that are responsible for their properties [16, 17]. These composites generally have modified or enhanced mechanical properties and dimensional stability, better fire retardancy, controlled permeability and melt processability, low cost. Mineral fillers increase the plastic's heat-deflection temperature, reduce their thermal expansion and change other performances as well. The minerals commonly fillers in plastic molding compounds include calcium carbonate, talc, silica, wollastonite, clay, mica, glass beads, alumina trihydrate [18, 19].

The article presents the scientific and technical contributions related to the achieving of a scalable procedure to improv thermal behavior and dimensional stability of PLA designed for 3D and 4D printing by controlling the morphology through nucleation and/or reinforcing with mineral filler. The novelty of the article is related to the fact that it tries to identify a solution for controlling the morphology of a type of PLA designed for 3D printing that already has higher crystallinity.

\section{Method and materials}

To improve thermal behavior and dimensional stability and to ensure optimal melt properties for shaping as filaments [20] with good behavior in printing technology, PLA was modified with additives which control the morphology through nucleation and/or reinforcing with mineral filler. PLA was selected as renewable polymer because it can be used both in 3D printing technologies and, after specific modifications, in 4D type those.

The effect of these additives was estimated by analyzing, before and after modification, both thermal (melting, crystallization, heat deflection temperature-HDT) and mechanical behavior (Izod impact resistance, tensile strength) and dimensional stability. The melting behavior was estimated after elimination the thermal history of the sample during the first heating. So that the melting behavior was estimated considering the second heating and the crystallization tendency by taking into account the cooling thermograms between the first and the second heating.

After the preliminary selection the selected composites were characterized by measuring their dimensional stability and, for the types without percentage change in size when subjected to temperature, in transverse or longitudinal direction, the shapability as filaments and also the printability of the resulted filaments was estimated. Composites selected as having desired thermo-mechanical properties, suitable dimensional stability and good shapability as filaments were scaled up and the printability of the filaments obtained from the new granules was subsequently checked.

\subsection{Compounding-shaping as filaments-3D printing. Materials}

A usual procedure for compounding and plates obtaining were used by working, in usually melt processing conditions, on the following laboratory devices: Brabender plasticorder $\left(180-200^{\circ} \mathrm{C}, 75 \mathrm{rpm}-\right.$ $120 \mathrm{rpm})$, roller $\left(60-70^{\circ} \mathrm{C}\right.$, friction:1) and a hydraulic press $\left(180-200^{\circ} \mathrm{C}, 13 \mathrm{~min}\right.$. pressing-8min cooling, 200 bar). Prior the compounding, PLA and hygroscopic filler were dried to remove excess moisture, 
under regular conditions (PLA: $70^{\circ} \mathrm{C}$, over night $(16 \mathrm{~h})$, talc: $103^{\circ} \mathrm{C}$ for $120 \mathrm{~min}$ ) [21-23]. Compounds with the following compositions were achieved: at 0.01\% -7.4\% nucleating agent LAK 301(NA) and/or $0.1 \%-43 \%$ talc and $1 \%-6 \%$ flow agents (fluorinated polymer, calcium stearate). The laboratory shapability as filaments of new compounds has been verified on a Brabender extruder by working in common conditions $\left(180-200^{\circ} \mathrm{C}, 50 \mathrm{rpm}\right)$. The selected compounds were scaled up on a line with the following devices: $50 \mathrm{~kg} / \mathrm{h}$ twin screw extruder $(\varphi=35.6 \mathrm{~mm}, \mathrm{~L} / \mathrm{D}=48$, compression ratio $=2.9$, heating zones $=9$, degassing zone and screen changer), water cooling bath, air dryer, granulator.The obtained granules were extruded into filaments for printing technology of 1.85 +/-0.05 mm diameter on a Gottfert mono screw extruder $\left(170-180^{\circ} \mathrm{C}, 150 \mathrm{rpm}\right)$, with line for filaments drawing, calibration, cooling and rolling $\left(90^{\circ} \mathrm{C}, 20^{\circ} \mathrm{C}, 80 \mathrm{rpm}\right)$. The 3D printability of the new filaments was tested on a UP! Plus 2 3D Printer, Z SPOT MEDIA SRL, 10-100 $\mathrm{cm}^{3} / \mathrm{h}$ printing speed, 140x140x135 mm printing size, self-generated model support, $0.20-0.40 \mathrm{~mm}$ or $0.15-0.35 \mathrm{~mm}$ layer thickness, STL file input format.

\subsection{Characterization}

\subsubsection{Thermal behavior}

Melting and crystallization temperature and associated enthalpy were measured by using DSC thermograms recorded in air atmosphere, on a DSC Du Pont 2000 instrument, in cycles with three runs: heating- cooling-heating. For the first run (first heating) the temperature was set from 20 to $200^{\circ} \mathrm{C}$ and heating rate of $10^{\circ} \mathrm{C} \cdot \mathrm{min}^{-1}$. After first heating, the samples were cooled down, with the same rate till $20^{\circ} \mathrm{C}$ and then it was heated again, till $250^{\circ} \mathrm{C}$ with the same rate.

Crystallinity was calculated according with [24] using values both of measured heat of fusion (melting enthalpy)- $\Delta H \mathrm{Hm}(\mathrm{J} / \mathrm{g})$, enthalpy of cold crystallization- $\Delta \mathrm{Hc}(\mathrm{J} / \mathrm{g})$ and $93.1(\mathrm{~J} / \mathrm{g})$, the enthalpy of fusion for $100 \%$ crystalline PLA and the weight fraction of the PLA.

Heat deflection temperature (polymer's ability to bear a given load at elevated temperatures): ISO 75 method B, load 0.46 MPa, analogous of ASTM D648.

\subsubsection{Functional properties}

Izod impact resistance: ISO 160, pendulum impact test fixture, un-noched samples of $80 \times 10 \times 4$ $\mathrm{mm}$;

Tensile resistance: ASTM D638, Instron testing equipment with extensometer, tensile strength and elongation at break $50 \mathrm{~mm} / \mathrm{min}$ and tensile modulus at $1 \mathrm{~mm} / \mathrm{min}$.;

Flexural strength and modulus: ISO 178, Instron testing equipment, sample of $10 \mathrm{~mm} \times 4 \mathrm{~mm} \times$ $80 \mathrm{~mm}, 1 \mathrm{~mm} / \mathrm{min}$.

\subsubsection{Dimensional stability}

Dimensional stability: Sizes changes of samples of $80 \times 10 \times 3 \mathrm{~mm}$, before and after, holding in air circulation oven, for $35 \mathrm{~min}$ at $180^{\circ} \mathrm{C}$.

\section{Results and discussions}

\subsection{Thermal behavior}

\subsubsection{Nucleation (compounds whit LAK 301)}

PLA is a semi-crystalline polymer that, in addition to the known usual crystallization, can sustain the cold crystallization (exothermic crystallization) and post melting crystallization [25]. The thermograms of the attained composites (Figure 1) no longer presents the exotherms characterizing the cold crystallization, having only a deep and narrow endothermic picks, with maximum of approx. the same temperature with neat PLA of $175^{\circ} \mathrm{C}$ (Figure 1a, Table 1).

If the neat PLA melts in a wide range between 168 and $179^{\circ} \mathrm{C}$, the compounds containing nucleating agent, depending on the formulation, melt in narrow range, either between 170 and $181^{\circ} \mathrm{C}$ or among 172 and $182^{\circ} \mathrm{C}$. Compared to the neat PLA which crystallizes in a wide range, from 90 to $110^{\circ} \mathrm{C}$ with maximum at $102,09^{\circ} \mathrm{C}$, depending on the concentration, the nucleant places the process in narrow ranges, 
but at higher temperature with aprox. $23^{\circ} \mathrm{C}-30^{\circ} \mathrm{C}$, respectively between 110 and $140^{\circ} \mathrm{C}$. The maximum crystallization picks are registered for neat PLA at $102.09^{\circ} \mathrm{C}$ and for new compounds, depending on the formulations, at temperature ranged from 116 to $139^{\circ} \mathrm{C}$ (Figure $1 \mathrm{~b}$, Table 1). Considering both these results and the crystallization enthalpies (Table 2) and the shape of the thermograms results that the nucleation agent increases the crystallinity and reduces the crystals sizes reason for which the crystallization exotherms are narrower and deeper and the melting enthalpies are tighter [26].

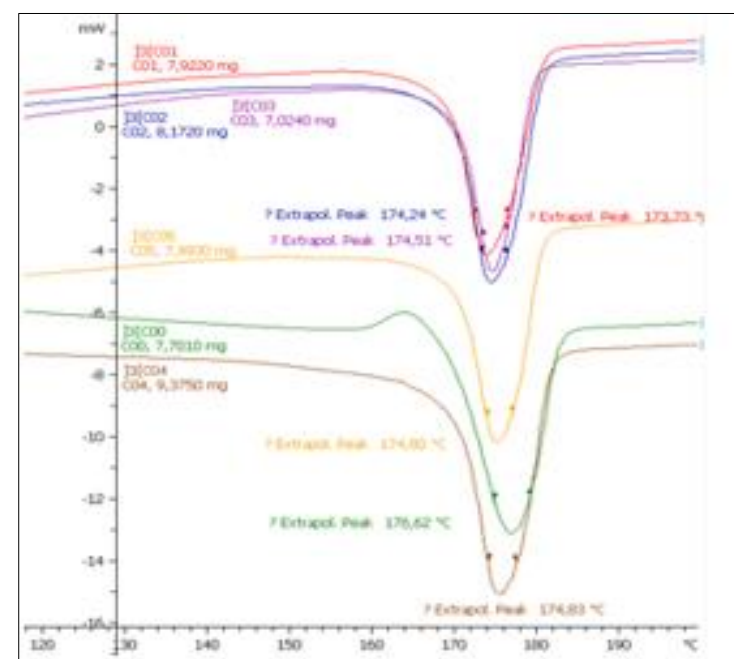

a)

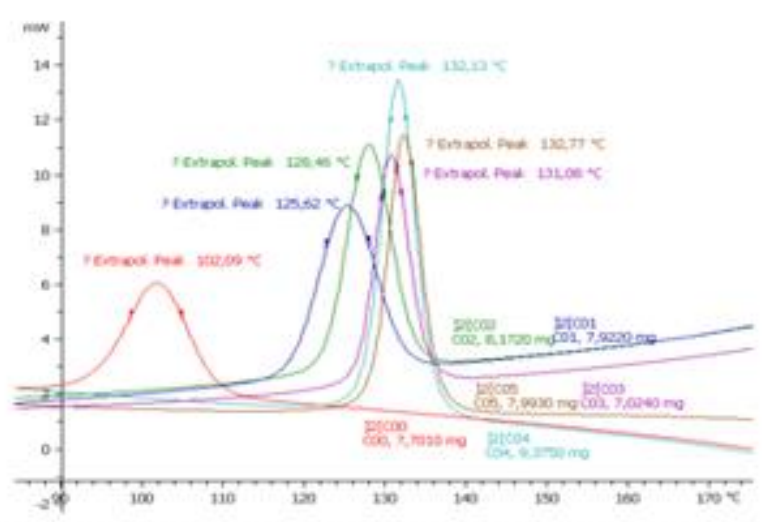

b)

Figure 1. Influence of the nucleant (NA) on the melting (a) and crystallization (b) of neat PLA-concentrations: (1-6) [\%] NA; C00- neat PLA; C01-1.5\% NA; CO2 -2 \% NA; $\mathrm{CO} 3-3.8 \% \mathrm{NA}$; $\mathrm{CO} 4-5.7 \% \mathrm{NA}$; $\mathrm{CO} 5-7.4 \% \mathrm{NA}$

The crystallization enthalpies are bigger, the higher is the amount of nucleant which probably means that high additivation level is required for a desired crystalinity of modified PLA. These results is in opposition with other ones which suggest the usage of this nucleating agent at low level [27]. The removal, because of the nucleation, of the cold crystallization, lying between 155 and $165^{\circ} \mathrm{C}$ for unmodified PLA, proves that the additive generates the increasing of the crystallization rate and at $10^{\circ}$ $\mathrm{C} / \mathrm{min}$ cooling rate, the crystals have time to be form and/or include fewer defects which could continue the process and the resulted new morphologies more homogeneous [25].

Table 1. Melting and crystallization behavior of nucleated PLA

\begin{tabular}{|c|c|c|c|c|c|}
\hline NA conc., $\%$ & $\mathbf{T m},{ }^{0} \mathrm{C}$ & Melting range, ${ }^{0} \mathrm{C}$ & Tcr., ${ }^{0} \mathrm{C}$ & Cristal. range, ${ }^{0} \mathrm{C}$ & $\Delta \mathrm{Tcr},{ }^{0} \mathrm{C}$ \\
\hline 0 & 176,62 & $168-179$ & 102,09 & $90-110$ & - \\
\hline 1.5 & 174,24 & $172-182$ & 125,62 & $116.02-133.10$ & 23.53 \\
\hline 2 & 174,51 & $172-182$ & 128,46 & $120.08-134.50$ & 26.37 \\
\hline 3.8 & 173,73 & $170-181$ & 132,77 & $124.02-138.02$ & 30.68 \\
\hline 5.7 & 174,80 & $170-181$ & 132,13 & $124.06-138.09$ & 30.04 \\
\hline 7.4 & 174,83 & $170-181$ & 131,08 & 124.08- 139.03 & 28.99 \\
\hline
\end{tabular}

Table 2. Melting and crystallization enthalpy of nucleated PLA

\begin{tabular}{|c|c|c|c|c|c|c|}
\hline \multirow{2}{*}{$\begin{array}{c}\text { Melting enthalpy \Crystal. enthalpy } \\
\text { Crystallinity\ NA concentration }\end{array}$} & \multicolumn{5}{|c|}{ \% Nucleant } \\
\cline { 2 - 7 } & Neat PLA & $\mathbf{1 . 5}$ & $\mathbf{2}$ & $\mathbf{3 . 8}$ & $\mathbf{5 . 7}$ & $\mathbf{7 . 4}$ \\
\hline$\Delta \mathrm{Hm}, \mathrm{J} / \mathrm{g}$ & 47.22 & 42.2 & 44.1 & 40.2 & 48.3 & 43.1 \\
\hline$\Delta \mathrm{Hc}, \mathrm{J} / \mathrm{g}$ & 32.18 & 40.2 & 41.2 & 38.1 & 42.6 & 39.3 \\
\hline Crytallinity, \% & 16.154 & 21.4 & 28.9 & 22.7 & 58.7 & 37,7 \\
\hline
\end{tabular}




\subsubsection{Modification with talc}

The influence of the micro-sized particles of talc on the morphology of PLA containing or not flow additives depends on the filling ratio and the reached dispersion of the filler into the PLA matrix (Figures 2-5 and Tables 3-6).

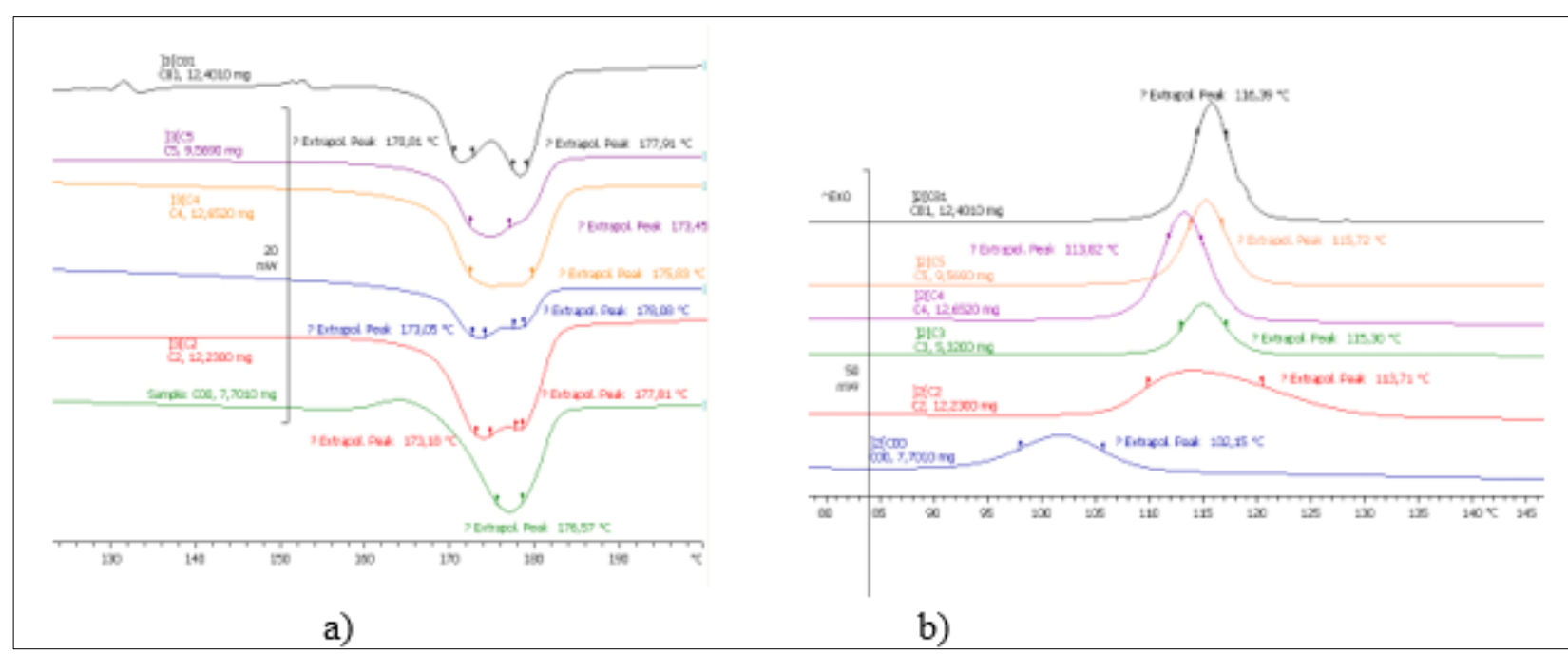

Figure 2. Influence of small level of micrometric talc (T) on the melting (a) and crystallization of the PLA D 850 based -composites (Talc level: 0.1 - $20 \%$; C00-control;

C2-0.1\% T; C3 -9\%; C4-4.8\%; C5-13\%; C81-20\%)

At small filling ratio of $1-13 \%$ talc, the cold crystallization ranged for the neat PLA between $155^{\circ} \mathrm{C}$ and $165^{\circ} \mathrm{C}$, is eliminated, as it happens in case of nucleation with NA. In contrast with the effect of NA, the melting endotherm is wide, split into two maxims, probably due to melting of two different crystal populations (Figure 2a, Table 3).

Table 3. Melting and crystallization behavior of neat PLA modificated with talc

\begin{tabular}{|c|c|c|c|c|c|}
\hline $\begin{array}{c}\text { Talc conc., } \\
\%\end{array}$ & $\begin{array}{c}\operatorname{Tm}_{1},{ }^{0} \mathrm{C} \\
/ \mathbf{T m}_{2},{ }^{0} \mathrm{C} \\
\end{array}$ & $\begin{array}{l}\text { Melting range, } \\
{ }^{0} \mathrm{C}\end{array}$ & Tcrist, ${ }^{0} \mathrm{C}$ & Crist.range, ${ }^{0} \mathrm{C}$ & $\Delta \mathrm{T}$ crist, ${ }^{0} \mathrm{C}$ \\
\hline 0 & 176.56 & $168-182$ & 102.15 & $96-109$ & \\
\hline 0.1 & $173.05 / 177.81$ & $170-184$ & 113.71 & $107.5-126.5$ & 11.56 \\
\hline 4.8 & $173.45 / 175.83$ & $170-186$ & 115.72 & $109.5-118$ & 13.57 \\
\hline 9 & $173.05 / 178.08$ & $170-182$ & 115.30 & $112-120$ & 13.15 \\
\hline 13 & $173.01 / 175.02$ & $170-184$ & 115.72 & $112-120$ & 13.57 \\
\hline 20 & $173.5 / 177.60$ & $170-182$ & 116.38 & $112-122$ & 14.30 \\
\hline 28.6 & $174.00 / 177.80$ & $172-182$ & 117.49 & $112-123$ & 15.34 \\
\hline 33.33 & $174.01 / 184.02$ & $172-182$ & 117.36 & $112-124$ & 15.21 \\
\hline 43 & $174.72 / 182.91$ & $172-184$ & 117.69 & $112-124$ & 15.54 \\
\hline
\end{tabular}

The existence of two different crystal populations had generated the overlapping of each population melting endotherm, every of them with own maximum, the first around $173^{\circ} \mathrm{C}$ and the second those, depending on the talc concentration, between 175 and $178^{\circ} \mathrm{C}$. As the talc concentration increases, the melting endotherms widen, the associated enthalpies diminishing with about $13-30 \%$, and the two melting maxima become more evident (Figure 2a, Table 3 and 4).

Table 4. Melting and crystallization enthalpy of neat PLA nucleated with micrometric talc

\begin{tabular}{|c|c|c|c|c|c|c|c|c|}
\hline \multirow{2}{*}{\begin{tabular}{c} 
Melting enthalpy $\begin{array}{c}\text { \% Talc } \\
\text { enthalpy } \backslash \text { Talc Conc. }\end{array}$ \\
\cline { 2 - 9 }$y$
\end{tabular}} & Neat PLA & $\mathbf{0 , 1}$ & $\mathbf{4 . 8}$ & $\mathbf{9}$ & $\mathbf{2 0}$ & $\mathbf{2 8 , 6}$ & $\mathbf{3 3 , 3}$ & $\mathbf{4 3}$ \\
\hline$\Delta \mathrm{Hm}, \mathrm{J} / \mathrm{g}$ & 47.49 & 40.81 & 38.1 & 36.3 & 34.33 & 27.15 & 26.6 & 20.3 \\
\hline$\Delta \mathrm{Hc}, \mathrm{J} / \mathrm{g}$ & 32.21 & 37.16 & 35.6 & 34.7 & 32.05 & 26.14 & 26.8 & 20.5 \\
\hline Cristallinity, \% & 16.412 & 38.81 & 25.4 & 20.3 & 19.59 & 7.74 & 4.58 & 1.84 \\
\hline
\end{tabular}


At higher talc level of $25-43 \%$, the melting behavior of the resulted compounds is approximately alike those of low talc concentration (Figure 3, Tables 3, 4).

Probably due to the melting of two different crystals populations, the melting endotherms appear to be the result of the overlapping of two different endotherms, each of them with individual peak, so that the entire melting endotherms appears to be split, more split as in case of the compounds with low concentration of talc. The melting range is wider, the melting enthalpy diminishing with about $30 \%$ $60 \%$ as compared with neat PLA, much more the talc concentration is higher (Table 4). Depending on the talc's level, the first melting peak has a maximum between 170 and $172^{\circ} \mathrm{C}$ and the second those being placed between 182 and $184^{\circ} \mathrm{C}$. These values are slightly higher than those found for the compounds with smaller talc concentration which means that, at higher talc concentrations, the melting range extends to elevated temperatures like for low compounds, but only with some degrees.

The crystallization of the compounds with small talc content $(0.1-13 \%)$ is represented by exotherms which extend between 110 and $126^{\circ} \mathrm{C}$ as compared with $96-109^{\circ} \mathrm{C}$ for neat PLA. This exotherms have a single maximum registered at higher temperatures with about $11-14^{\circ} \mathrm{C}$ as for the neat PLA. The crystallization enthalpies of these compounds are higher with about $6-15 \%$ as for unmodified PLA, which means a higher crystallinity (Figure 2b, Table 3).

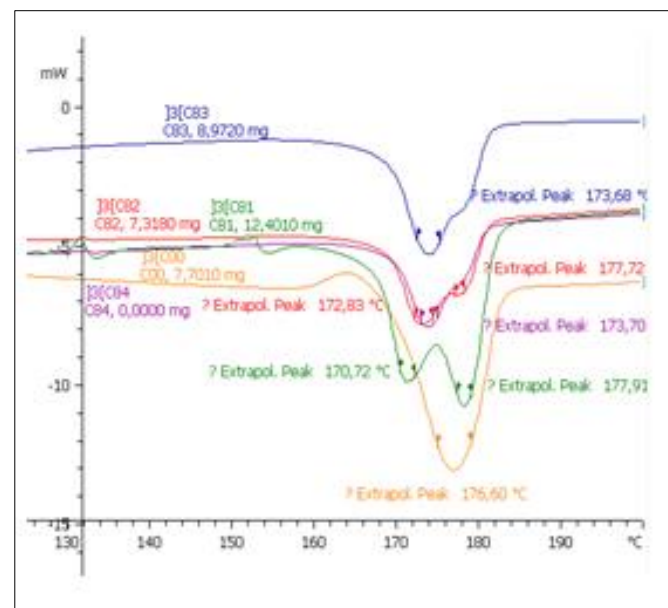

a)

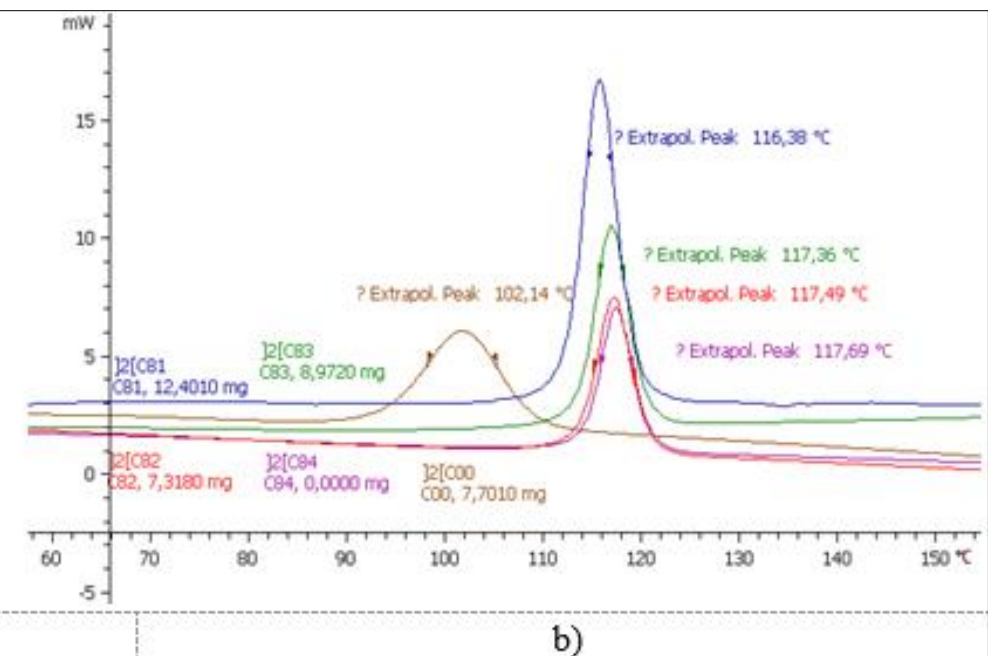

b)

Figure 3. The influence of micrometric talc (T) on the melting (a) and crystallization (b) of the PLA D 850 based-composites (Level of T: 20\%-43 \%; C00-control; C81-20 \%; C82 -28.6 \%; C83-33.3\%; C84-43\%) (Capitol 3.1.2.)

The crystallization exotherms of the compounds with high talc content (20-43\%), has also a single and narrow peak with maximum at a temperature higher with almost $14-15^{\circ} \mathrm{C}$ as the crystallization pick of the neat PLA (Table 4). The pick of the neat PLA is registered at approx. $102^{\circ} \mathrm{C}$ and between 115 and $124^{\circ} \mathrm{C}$ for these compounds, which means $13-22^{\circ} \mathrm{C}$ higher. The crystallization enthalpy and the crystallinity decreases further, as higher is the talc concentration becoming almost non-existing for the compound with $43 \%$ talc (Table 4 ).

The melting in wide temperature range with two maxims, especially at high talc level is not an advantage for $3 \mathrm{D}$ printing considering the melting of the filaments phase, especially at high talc's level when the flow instability may occur [28].

The melting peaks appear broader or narrow, higher or lower mainly depending on both the microscale morphological order of the obtained composites [29] and the registration DSC conditions [30]. Considering the used registering conditions, it was appreciated that the DSC thermograms shape is connected with the composites morphology generated by the talc's presence, mainly the efficiency of its dispersion degree into the PLA matrix. That is why, a first attempt has been made to narrowing the melting endotherms and to eliminate theirs splitting by formulating with certain flow agents used in various concentrations (Figures 4, 5, Tables 5, 6). 
With the exception of the NA, the two flow agents do not eliminate the melting with two peaks, but slightly increase the melting enthalpies which means a little higher crystallinity because of the improved dispersion of the talc into the polymeric matrix. In addition, the composites with M3 or Ca stearate melt in a widen and lower temperature range, features more pronounced at higher concentration of the flow agent (Figures 4a, 5a, Table 6). The formulation with flaw agents narrows and moves to higher temperatures the picks of the crystallization exotherms, the more at higher levels of the additives (Figures $4 \mathrm{~b}, 5 \mathrm{~b}$, Table 6). The used flow agents changed the melting and crystallization features of the PLA-talc composites but didn't improve them to be fulfilled the requirements of the printing technology (narrow melting and crystallization ranges).

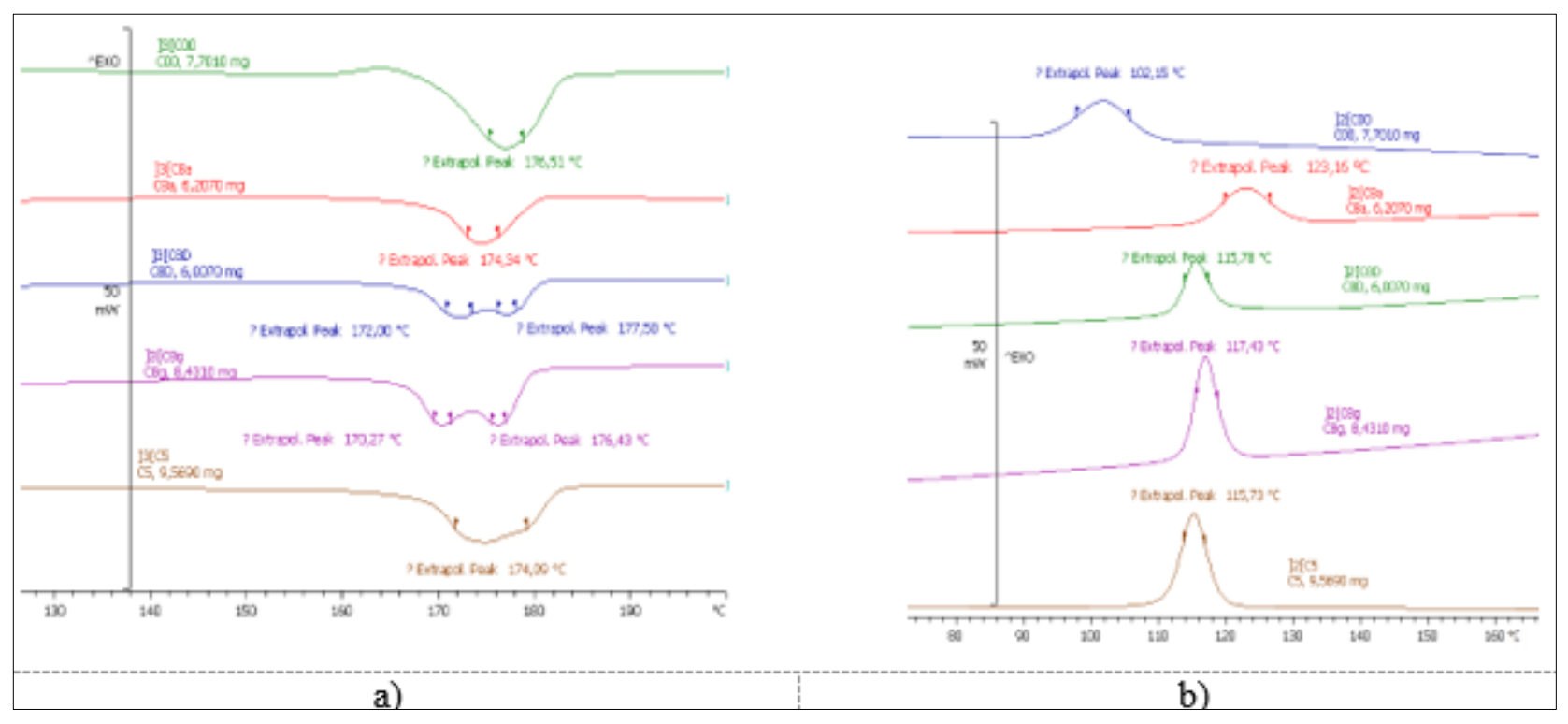

Figure 4. Melting and crystallization of PLA D 850 modified with micro talc and small amount of flow additives (Concentrations $1 \%$ / (87 \% neat PLA + $13 \%$ Talc); C00-neat PLA; C5- (87 \% neat

The combination of nucleating agent with reinforcing agent is the exception, because the melting is no longer split, the endotherme is even narrowed, and the crystallization is range with about $10-15^{\circ} \mathrm{C}$ higher than for the composites only with reinforcing filler. The higher the concentration of NA, the more obvious is the tightening of the melting range (Figure 4a-curve C8a, Figure 5a-curve C8c). The explanation is related most probably to the overlap of a nucleation process generated by NA with a reinforcing one originated in high amount of talc of these composites.

Table 5. Thermal behavior of neat PLA modificated with talc and NA or flow agent

\begin{tabular}{|c|c|c|c|c|c|}
\hline Additive concentration, $\%$ & $\mathrm{Tm}_{1},{ }^{0} \mathrm{C} \quad \mathrm{Tm}_{2},{ }^{0} \mathrm{C}$ & Melting range, ${ }^{\circ} \mathrm{C}$ & Tcr., ${ }^{0} \mathrm{C}$ & Crist.range, ${ }^{0} \mathrm{C}$ & $\Delta \mathrm{Tcr},{ }^{0} \mathrm{C}$ \\
\hline Martor & 176.56 & $168-182$ & 102.15 & 96-109 & \\
\hline $13 \% \mathrm{~T}$ & $\begin{array}{ll}173.01 & 175.02 \\
\end{array}$ & $170-184$ & 115.72 & $112-120$ & 13.67 \\
\hline $1 \% \mathrm{NA} / 13 \% \mathrm{~T}$ & 174.34 & 170 - 182 & 123.16 & 118-132 & 21.16 \\
\hline $1 \% \mathrm{M} 3 / 13 \% \mathrm{~T}$ & $172 \quad 177$ & $168-181$ & 115.78 & $113-120$ & 13 \\
\hline $1 \% \mathrm{CaSt} / 13 \% \mathrm{~T}$ & $170.27 \quad 176.43$ & $167-181$ & 117.43 & 114-119 & 15 \\
\hline $5 \% \mathrm{NA} / 13 \% \mathrm{~T}$ & 176.50 & 172-179 & 12931 & 126-134 & 27 \\
\hline $5 \% \mathrm{M} 3 / 13 \% \mathrm{~T}$ & $170.81 \quad 177.2$ & $168-179$ & 115.31 & $113-121$ & 13 \\
\hline $5 \% \mathrm{CaSt} / 13 \% \mathrm{~T}$ & 171 & $163-179$ & 118.41 & $115-123$ & 16 \\
\hline
\end{tabular}

Considering the obtained results, it can be underlined that as it was known, depending on the concentration, talc has a double role of nucleating agent or reinforcing agent. For the concentration range at which the melting and crystallization enthalpy increase, the talc modifies the PLA morphology by nucleation and it acts as reinforcing filler from the concentration at which these two enthalpies begin to decrease. Taking into account also that the used talc contains particles with wide size distribution (Figure 
6), in the studied range of concentration up to approx. $9 \%$ it acts as a nucleating agent and between 13 and $41 \%$ it has a reinforcing effect.

Table 6. Melting and crystallization enthalpy of neat PLA modified with T and flow agent

\begin{tabular}{|c|c|c|c|c|c|c|c|c|}
\hline \multirow{3}{*}{$\begin{array}{c}\text { Enthalpy }(\Delta \mathrm{Hc}), \mathrm{J} / \mathrm{g} \backslash \\
\text { Crystallinity, \%/ Samples }\end{array}$} & \multirow{3}{*}{ Neat PLA } & \multirow{3}{*}{$\begin{array}{c}\text { PLA with } 13 \\
\% \mathrm{~T}\end{array}$} & \multicolumn{6}{|c|}{ [\%] NA or Flow agent in (87 \% PLA with $13 \%$ T) } \\
\hline & & & \multicolumn{2}{|c|}{ NA } & \multicolumn{2}{|c|}{ M3 } & \multicolumn{2}{|c|}{ CaSt } \\
\hline & & & 1 & 5 & 1 & 5 & 1 & 5 \\
\hline$\Delta \mathrm{Hm}$ & 47.12 & 33.2 & 30.67 & 32 & 34.2 & 34.5 & 37.5 & 36.7 \\
\hline$\Delta \mathrm{Hc}$ & 32.23 & 31.2 & 30.39 & 31.8 & 31.2 & 32.0 & 34.1 & 35.2 \\
\hline Cristallinity & 16.41 & 21.3 & 29.7 & 24.3 & 31.9 & 25.2 & 15.4 & 15 \\
\hline
\end{tabular}

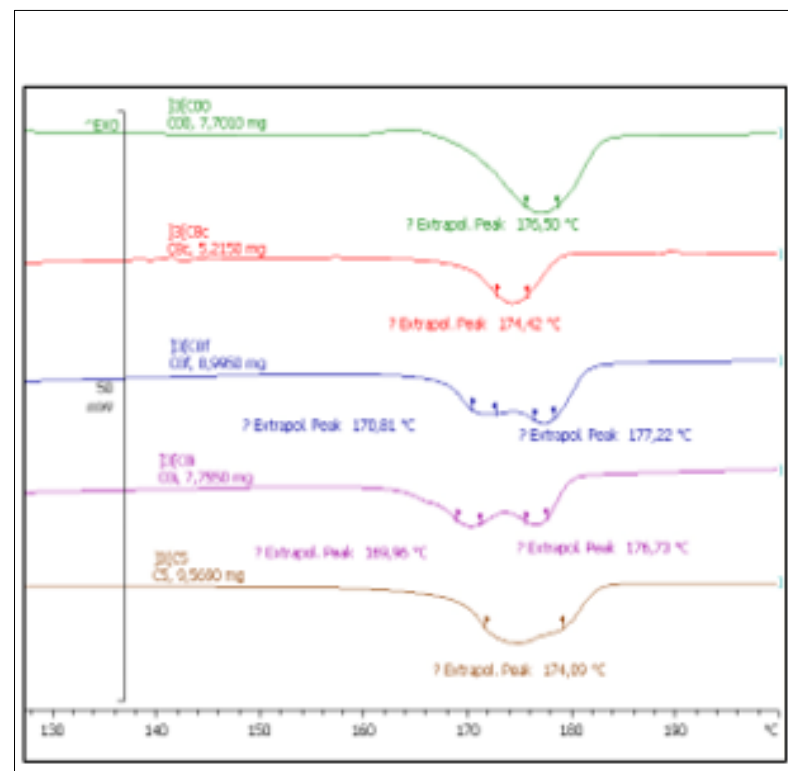

a)

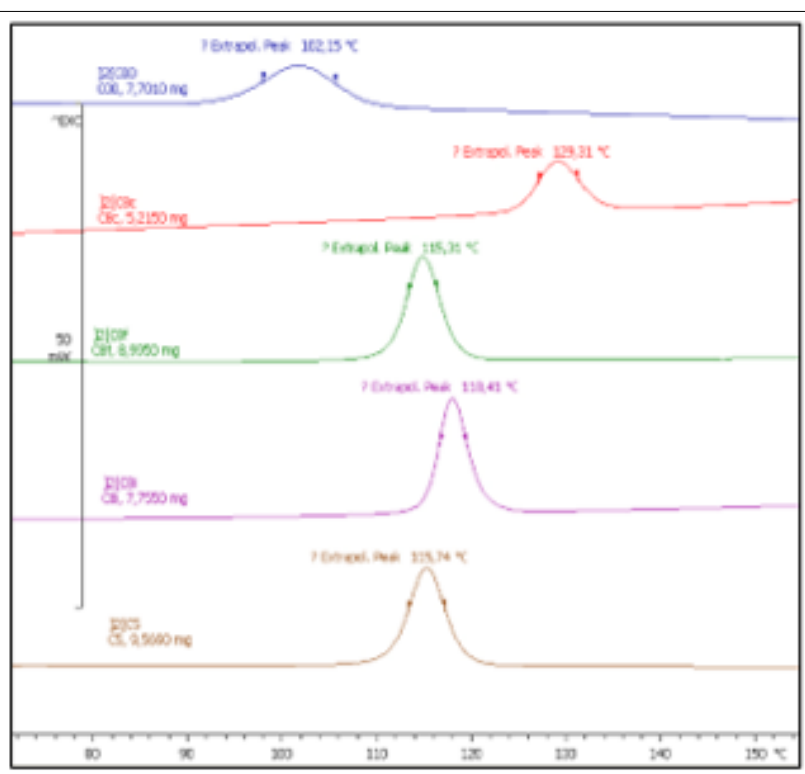

b)

Figure 5. Melting and crystallization of neat PLA modified with micro talc and medium amount of flow additives (Concentrations $6 \%$ / (81 \% neat PLA + $13 \%$ Talc); C00-neat PLA; C5-(87 \% neat PLA+ $13 \%$ talc; C8c-6\% AN; C8f-6\% M3; C8i-6\% Ca Stearate

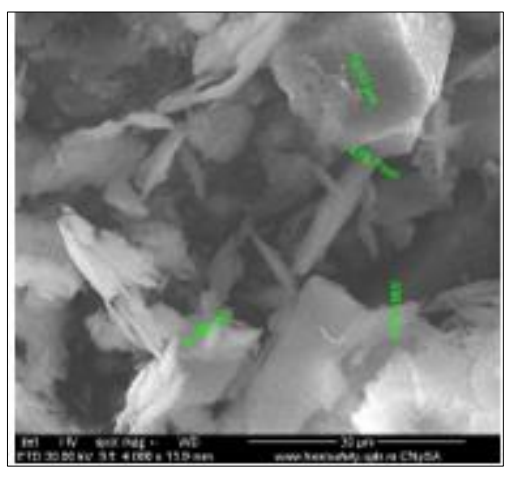

Figure 6. The size of the talc particles used to control the morphology of PLA designed for printing technology

The size of the used micrometric talc particles is ranged from $0.002 \mu \mathrm{m}$ to $360 \mu \mathrm{m}$ which means a very wide size can be a possible explanation for the existence of the two majority crystals populations with individual melting pick, as described earlier. Considering the existence on the crystallization exotherm only of a narrow pick, it appears that during this process almost similar crystals population is formed. The splitting of the melting endotherm may result from that only nanometric talc particles are involved in the crystallization and depending on the conditions in which this process takes place but also on the formulation by the simultaneous use of a nucleating agent too, a crystal population or more can be formed. All these aspects will be elucidated in the future works. 
The known information considering the concentration range at which the nucleation effect of talc differs from the reinforcing those are contradictory. According to [23], talc acts as nucleating agent at small concentration of $3-6 \%$. In [24] it was found that talc with median diameter of $0.9 \mu \mathrm{m}$, and specific gravity of $2.8 \mathrm{~g} / \mathrm{cm}^{3}$ has the role of nucleating agent in a wide concentration raged, respectively of 10 $30 \%$. Other results regarding the double role of talc in PLA modification do not specify the talc concentrations which separates the talc action as nucleating agent from the behavior as reinforcing filler [31]. It is possible that the level of talc which make the difference between its behavior as nucleator or reinforcing filler depends primarily on the size and the distribution size of the talc particles.

\subsection{Dimensional stability}

The percentage change in size of neat PLA subjected, 40 min to $70^{\circ} \mathrm{C}$, in air circulation oven is 4,5 $\%$ in the transverse direction, the landing value being reached after approx. $25 \mathrm{~min}$. and of $1.5 \%$ in longitudinal path. The composites with nucleator and/or its combinations of nucleator with reinforcing agent, do not reveal any changes in size, after the same heat treatment (Figure 7) probably because the mobility of the macromolecules are hindered as they are trapped in morphological structures as crystals and/or reinforced areas [32].

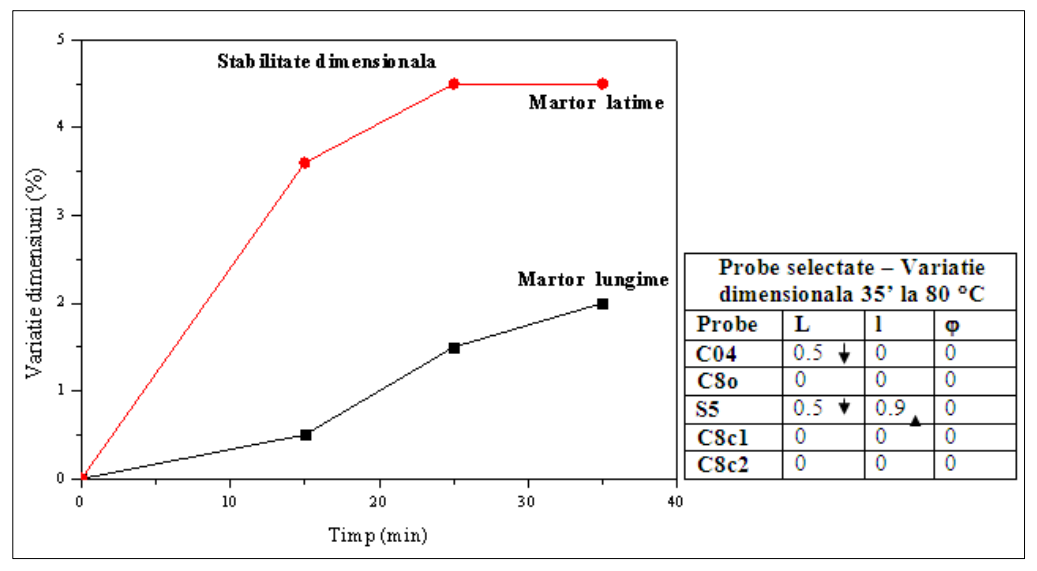

Figure 7. Dimensional stability of neat PLA and PLA-modified with nucleant and/or inorganic filler

\subsection{Shapability and printability of selected compounds. Functional properties}

The shapability of the selected formulations with properties as in Table 10 was checked first at laboratory scale and then, the compositions which led to filaments with smooth appearance and constant diameter, were scaled-up, for almost $8 \mathrm{~h}$ of continuous extrusion. During extrusion did not register melt fracture, swelling or other flow defects and the resulting filaments had uniform and smooth surface, good ovality and constant diameter of $1.85+/-0.05 \mathrm{~mm}$ (Figure 8 ). The scaled up filaments were easily cut into uniform in size and appearance granules, had properties according to table 10 and a good 3D printing behavior (Figure 8).

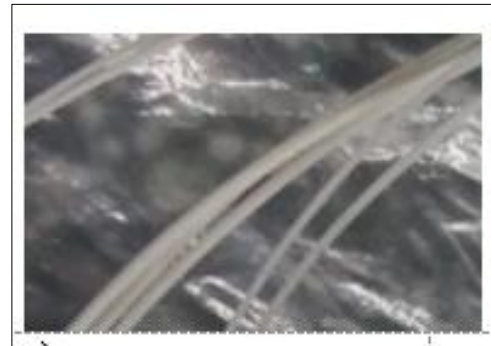

a)

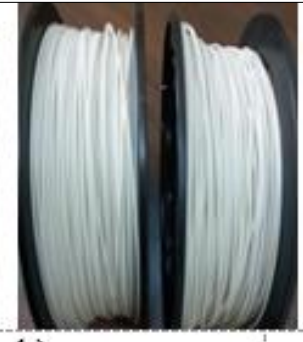

b)

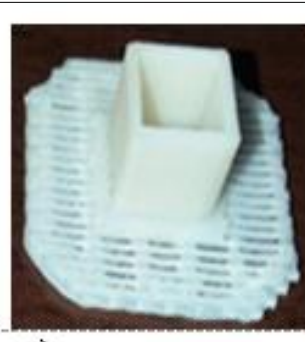

c)

Figure 8. Filaments achieved at laboratory (a), on industrial installation (b) and items 3D printed (c) from PLA modified through nucleation and reinforcing 
Table 10. Functional properties of PLA modified with different nucleating and/or filler or other additives (laboratory and scaled-up results)

\begin{tabular}{|c|c|c|c|}
\hline \multirow[b]{2}{*}{ Properties, UM, Method", Conditions" } & \multicolumn{3}{|c|}{ Property variation range of property } \\
\hline & Neat PLA & Laboratory formulation ${ }^{2 *}$ & $\begin{array}{c}\text { Scaled up } \\
\text { formulation }^{2^{*}}\end{array}$ \\
\hline Melting temperature range, ${ }^{0} \mathrm{C}$ & $160-182$ & $170-185$ & $170-180$ \\
\hline Crystallization range, ${ }^{0} \mathrm{C}$ & $87-105$ & $80-135$ & $125-135$ \\
\hline Tensile modulus, $\mathrm{MPa}, \mathrm{v}=50 \mathrm{~mm} / \mathrm{min}$, & 2356 & $2200-3000$ & $3097(+/-06)$ \\
\hline Flexural strength, $\mathrm{MPa}, \mathrm{v}=2 \mathrm{~mm} / \mathrm{min}$ & 88.3 & $80-90$ & $91.8(+/-0.07)$ \\
\hline Flexural modus, $\mathrm{MPa}, \mathrm{v}=2 \mathrm{~mm} / \mathrm{min}$ & 2863 & $2700-3100$ & $3120(+/-0.05)$ \\
\hline Izod impact resistance, unnoched, $\mathrm{J} / \mathrm{m}^{2}$ & 0.5 & $1-15$ & $5.69(+/-0.1)$ \\
\hline HDT. ${ }^{0} \mathrm{C}$ & 70 & $70-150$ & 100 \\
\hline Densitate, $\mathrm{g} / \mathrm{cm}^{3}$ & 1.23 & $1.24-1.37$ & 1.35 \\
\hline Dimensional stability, \%, (L/ T) & $4.5 / 1.5$ & $0.5-4.5 / 0.1-1.5$ & $0 / 0$ \\
\hline
\end{tabular}

*See subchap. $2.3 ;{ }^{2 *}$ - Complex formulations with or without nucleating agent and/or reinforcing agent and/or flow agents, other additives

The novelty of the article is related to the fact that it identifies a solution for modifying a type of PLA designed for 3D printing that already has a morphology with advanced crystallinity. This solution is based on a certain combination of tested nucleation agents.

\section{Conclusions}

The paper presents the scientific and technical contributions concerning the melt modification of PLA with nucleating agents and/or inorganic filler (talc) with obtaining of PLA-based compounds with controlled morphology that preserves the advantages of PLA and eliminates the deficiencies regarding thermal behavior and dimensional stability and can be use both in 3D and 4D printing technology.

The novelty of the article is related to the fact that it identifies a solution for modifying a type of PLA designed for 3D printing that already has a morphology with advanced crystallinity. This solution is based on a certain combination of tested nucleation agents.

The used nucleation agent generates the narrowing of the melting and mainly of crystallization picks which means advantages it 3D and 4D printing because the processes of melting of filaments and then those of crystallization during cooling after obtaining of the new items will take place in narrow temperature ranges, easy to be controlled in practical conditions. The higher the concentration of NA, the more obvious is the tightening of the melting and crystallization range. Because of nucleation the crystallization range is placed approximately $30^{\circ} \mathrm{C}$ higher than for the neat PLA which is another advantage for printing technologies because it facilitates the cooling phase of the products obtained by printing.

Depending on the talc concentrations, the new compounds present variable crystallinity, lower the amount of talc is higher. It was considered that for the concentration range at which the melting and crystallization enthalpy increase, the talc modifies the PLA morphology by nucleation and it acts as reinforcing filler from the concentration at which these two enthalpies begin to decrease. It was observed that up to approx. 9\%, talc acts as nucleating agent and between 13 and $41 \%$ it has a reinforcing effect. It is possible that the level of talc which makes the difference between its behavior as nucleator or reinforcing filler depends primarily on the size and the distribution size of the talc particles.

The combination of nucleating agent with reinforcing filler those preserved the advantages of both of them. The melting is no longer split, the endotherms is even narrowed, and the crystallization range is with about $10-15^{\circ} \mathrm{C}$ higher than for the composites only with reinforcing filler. The flow agent slightly improves the dispersion of talc in the base polymeric matrix.

The selected formulations where scaled-up after several selection stages considering the thermomechanical properties and reach dimensional stability. The shapability of the scaled up obtained granules as $3 \mathrm{D}$ printed filaments and the 3D printability of these filament were also checked with good results. 
Acknowledgments: This work was supported by grants of the Romanian Ministry of Research and Innovation, CCCDI - UEFISCDI, project number nos.23 N/2019, PCCE 40-2018 (project 5/3D-LONG LIFE), 52CI/2017. The authors also thank to their colleagues involved in obtaining and characterization of the new compounds.

\section{References}

1.A. SHAKOOR, N.L. THOMAS., 2013. "Talc as a nucleating agent and reinforcing filler in poly(lactic acid) composites." Polymer Engineering and Science 64-70. doi:doi.org/10.1002/pen.23543.

2.AGARWALA, SHWETA. 2016. "A Perspective on 3D Bioprinting Technology: Present and." American Journal of Engineering and Applied Sciences 9 (4): 885-990.

doi:10.3844/ajeassp.2016.985.990.

3. ***n.d. "Dimensional Stability ASTM D1204."

4.DOINA DIMONIE, CELINA DAMIAN, ROXANA TRUSCA, MARIA RAPA. 2019. "Some Aspects Conditioning the Achieving of Filamentsfor 3D Printing from Physical Modified Corn Starch,

Mater. Plast., 56(2), 2019, 351-359.

5.ELIZABETH AZHIKANNICKAL, AARON UHRIN. 2019. "Dimensional Stability of 3D Printed Parts: Effects of Process Parameters." Ohio Journal of Science 119 (2): 9.

doi:doi.org/10.18061/ojs.v119i2.6593.

6.EROGLU, MEHMET. 2007. "Effect of Talc and Heat Treatment on the Properties of Polypropylene/ EVA Composit." International Journal of Science \& Technology 2 (1): 63-73.

7.FENGMEI YU, TAO LIU, XIULI ZHAO, XUEJIANG YU, AI LU, JIANHUA WANG. 2012. "Effects of talc on the mechanical and thermal properties of polylactide." Applied Polymer Science 125 (S5).doi:doi.org/10.1002/app.36260.

8.GE WANG, IAN R.HARRISON. 1994. "Polymer melting: heating rate effects on DSC melting peaks." (Thermochimica Acta) 231 (10): 203-213. doi:doi.org/10.1016/0040-6031(94)80023-5.

9.GIOVANNA GROSSO, ENRICO M.TROISI, NICK O.JAENSSON, GERRIT W.M.PETERS, PATRICK D.ANDERSON. 2019. "Modelling flow induced crystallization of IPP: Multiple crystal phases and morphologies." Polymers 182 (7): 121806. doi:doi.org/10.1016/j.polymer.2019.121806.

10.GUO, QIPENG. 2016. Polymer Morphology: Principles, Characterization, and Processing.

11.HEATHER SIMMONS, PRAPHULLA TIWARY, JAMES E.COLWELL, MARIANNA KONTOPOULOU. 2019."Improvements in the crystallinity and mechanical properties of PLA by nucleation and annealing." (Polymer Degradation and Stability) 116: 248-257.

doi:doi.org/10.1016/j.polymdegradstab.2019.06.001.

12.JANESCHITZ-KRIEGL, HERMANN. 2018. "Crystallization Modalities in Polymer Melt Processing." Springer International Publishing.

13.JEFFREY W.STANSBURY, MIKE J.IDACAVAGe. 2016. "3D printing with polymers: Challenges among expanding options and opportunities." Dental Materials 32 (1): 54-56.

doi:doi.org/10.1016/j.dental.2015.09.018.

14.JESSICA TORRES, CHENGQING WANG, BRYAN COUGHLIN, JOHN BISHOP, RICHARD REGISTER, ROBERT RIGGLEMAN, CHRISTOPHER STAFFORD, BRYAN VOGT. 2011. "Influence of Chain Stiffness on Thermal and Mechanical Properties of Polymer Thin Films." Macromolecules 44 (22): 9040-9045. doi:doi.org/10.1021/ma201482b.

15.JOEL D. SHORE, DAVID RONIS, LUC PICHE. 1997. "Theory of melt fracture instabilities in the capillary flow of polymer melts." (Physical Review) 55 (3): 2976-2992. doi:10.1103/PhysRevE.55.2976. 16.K. K. KHANUM, ARATHI MOHAN SHARMA, FAISAL ALDAWSARI, C. ANGAMMANA, S. JAYARAM. 2020. "Influence of Filler-Polymer Interface on Performance of Silicone Nanocomposites." IEEE Transactions on Industry Applications 56 (1): 686-692. doi:10.1109/TIA.2019.2943445.

17.LONG YU, HONGSHENG LIU, KATHERINE DEAN, LING CHEN. 2008. "Cold crystallization and postmelting crystallization of PLA plasticized by compressed carbon dioxide." (Journal of Polymer Science/ Part B Polymer Physics). doi:doi.org/10.1002/polb.21599. 
18.M.C.TANZI. 2017."6-Characterization of thermal properties and crystallinity of polymer biomaterials." (Characterization of Polymeric Biomaterials) 123-146.

doi:doi.org/10.1016/B978-0-08-100737-2.00006-6.

19.MICHAEL C. ZHANG, BAO-HUA GUO, JUN XU. 2017. "A Review on Polymer Crystallization Theories." Chrystals 7 (4). doi:doi.org/10.3390/cryst7010004.

20.MRAZ, STEPHEN. 2015. "Mineral Fillers Improve Plastics." MachineDesign. Accessed August 20, 2020. https://www.machinedesign.com/materials/article/21834429/mineral-fillers-improve-plastics.

21.NICOLAS DELPOUVE, LAURENT DELBREILH, GREGORY STOCLET, ALLISSON SAITER, ERIC DARGENT. 2014. "Structural Dependence of the Molecular Mobility in the Amorphous Fractions of Polylactide." Macromolecules 15 (5186-5197): 47. doi:doi.org/10.1021/ma500839p.

22.PENG GENG, JI ZHAO, WENZHENG WU, YULEI WANG, BOFAN WANG, SHUOBANG WANG, GUIWEI LI. 2018. "Effect of Thermal Processing and Heat Treatment Condition on 3D Printing PPS Properties." Polymers 10: 875. doi:10.3390/polym10080875.

23.***2017. Polymer Crystallization I. Springer International Publishing.

24.REN, KANGTAI. 2015. "Stereolithography: Three Decades of UV Technology Innovation." June 3. Accessed August 15, 2020. https://uvebtech.com/articles/2015/stereolithography-three-decades-of-uvtechnology-innovation/.

25.SCHULTZ, J. M. 1997. Properties of Solid Polymeric Materials. Elsevier academic Press.

26.SHADY FARAH, DANIEL G.ANDERSONA, ROBERT LANGERA. 2016. "Physical and mechanical properties of PLA, and their functions in widespread applications - A comprehensive review." Advanced Drug Delivery Reviews 107 (15): 367-392. doi:doi.org/10.1016/j.addr.2016.06.012. 27.SHIJUN WANG, SHICHEN YUAN, KUN WANG, WEI CHEN, KOJI YAMADA, DEBORAH BARKLEY, TADANORI KOGA, YOU-LEE HONG, TOSHIKAZU MIYOSHI. 2019. "Intramolecular and Intermolecular Packing in Polymer Crystallization." Macromolecules 52 (12): 4739-4748. doi:doi.org/10.1021/acs.macromol.9b00702.

28.WANGWANG YU, XINZHOU WANG, ELEONORA FERRARIS, JIE ZHANG. 2019. "Melt crystallization of PLA/Talc in fused filament fabrication." Materials \& Design 182 (15): 08013.

doi:doi.org/10.1016/j.matdes.2019.108013.

29.WANGWANG YU, XINZHOU WANG, ELEONORA FERRARIS, JIE ZHANG. 2019. "Melt crystallization of PLA/Talc in fused filament fabrication." (Materials \& Design) 182 (15).

doi:10.1016/j.matdes.2019.108013.

30.WOLFF, ERNEST G. 2004. Introduction to the Dimensional Stability of Composite Materials. 31.XANTHOS, MARINO. 2010. Functional Fillers for Plastics, 2nd Edition, Updated and Enlarged. Edited by Marino Xanthos

32.YAMING WANG, MING LI, CHANGYU SHEN. 2011. "Effect of constrained annealing on the microstructures of extrusion cast polylactic acid films." Materials Letters 65 (23-24): Pages 3525-3528. doi:doi.org/10.1016/j.matlet.2011.07.090

Manuscript received: 30.08 .2020 